\title{
Neural Control of Unloaded Leg Posture and of Leg Swing in Stick Insect, Cockroach, and Mouse Differs from That in Larger Animals
}

\author{
Scott L. Hooper, ${ }^{1,2 \star}$ Christoph Guschlbauer, ${ }^{2 \star}$ Marcus Blümel, ${ }^{2}$ Philipp Rosenbaum, ${ }^{2}$ Matthias Gruhn, ${ }^{2}$ Turgay Akay, ${ }^{3}$ \\ and Ansgar Büschges ${ }^{2}$ \\ ${ }^{1}$ Department of Biological Sciences, Ohio University, Athens, Ohio 45701, ${ }^{2}$ Tierphysiologie, Zoologisches Institut, Universität zu Köln, 50931 Köln, \\ Germany, and ${ }^{3}$ Department of Biochemistry and Molecular Biophysics, Columbia University, New York, New York 10032
}

Stick insect (Carausius morosus) leg muscles contract and relax slowly. Control of stick insect leg posture and movement could therefore differ from that in animals with faster muscles. Consistent with this possibility, stick insect legs maintained constant posture without leg motor nerve activity when the animals were rotated in air. That unloaded leg posture was an intrinsic property of the legs was confirmed by showing that isolated legs had constant, gravity-independent postures. Muscle ablation experiments, experiments showing that leg muscle passive forces were large compared with gravitational forces, and experiments showing that, at the rest postures, agonist and antagonist muscles generated equal forces indicated that these postures depended in part on leg muscles. Leg muscle recordings showed that stick insect swing motor neurons fired throughout the entirety of swing. To test whether these results were specific to stick insect, we repeated some of these experiments in cockroach (Periplaneta americana) and mouse. Isolated cockroach legs also had gravityindependent rest positions and mouse swing motor neurons also fired throughout the entirety of swing. These data differ from those in human and horse but not cat. These size-dependent variations in whether legs have constant, gravity-independent postures, in whether swing motor neurons fire throughout the entirety of swing, and calculations of how quickly passive muscle force would slow limb movement as limb size varies suggest that these differences may be caused by scaling. Limb size may thus be as great a determinant as phylogenetic position of unloaded limb motor control strategy.

\section{Introduction}

Understanding how nervous systems control posture and movement is a fundamental goal of neurobiology. Muscle transforms neural output into action. The consequences of motor neuron activity therefore cannot be understood without understanding this transformation (see Chiel and Beer, 1997, for a full discussion of this issue). Work on the pyloric muscles of the lobster stomatogastric system well demonstrates this issue (Morris and Hooper, 1998; Morris et al., 2000; Thuma et al., 2003). Pyloric motor neurons fire bursts of action potentials approximately once per second. Pyloric muscles might therefore be assumed to shorten and lengthen with each motor neuron burst. However, these muscles are much too slow to do so, and instead either

\footnotetext{
Received Nov. 10, 2008; revised Feb. 19, 2009; accepted Feb. 22, 2009.

This work was supported by a guest professorship from the Universität zu Köln and a Mercator Professorship from the Deutsche Forschungsgemeinschaft to S.L.H., by grants from the National Institute of Mental Health to S.L.H., the Howard Hughes Medical Institute to T.A., and the Deutsche Forschungsgemeinschaft, the Institute for Advanced Study in Berlin, and the Boehringer-Ingelheim Foundation to A.B. We thank H. Scharstein for discussion of scaling issues and measurement of human knee oscillation decline time constant; R. Full, P. Holmes, and V. Dürr for discussions in the course of this work; the Mathematical Bioscience Institute at Ohio State University for hosting a Neuromechanics of Locomotion Conference at which some of these discussions took place; and R. A. DiCaprio, K. H. Hobbs, B. R. Johnson, B.Ch. Ludwar, J. Schmidt, and J.B. Thuma for comments on this manuscript.

*S.L.H. and C.G. contributed equally to the initiation of this work.

Correspondence should be addressed to Scott L. Hooper, Neuroscience Program, Department of Biological Sciences, Irvine Hall, Ohio University, Athens, 0H 45701. E-mail: hooper@ohio.edu.

D01:10.1523/JNEUROSCI.5510-08.2009

Copyright $\odot 2009$ Society for Neuroscience $\quad$ 0270-6474/09/294109-11\$15.00/0
}

produce sustained, tonic contractions, or contract and relax in phase with modulations imposed on pyloric motor neuron activity by other, more slowly cycling, stomatogastric neural networks. Understanding the functional consequences of motor neuron activity in this system is thus impossible without knowing muscle response to motor neuron input.

It could be argued that this example is a special case. Muscles controlling limbs, which in general can move rapidly, and whose movements are believed to be often subject to moment-bymoment control, might be expected to respond rapidly to changes in motor neuron activity. We were therefore surprised to find that stick insect leg muscles are slow (Guschlbauer et al., 2007; Hooper et al., 2007a,b). These data suggested that it was important to reexamine neural control of limb posture and movement in this species (for review of previous work see Bässler and Büschges, 1998, and Büschges and Gruhn, 2008). To limit these investigations to particularly simple situations, we examined neural control under conditions (unloaded limb posture, swing phase in walking) in which only the limb's own mass is controlled. We report here that neural control in stick insect indeed differs from that in several species with more rapid muscles (Prochazka et al., 1989; Tokuriki and Aoki, 1995). However, these organisms are also much larger then stick insects. To control for this size difference, we examined neural control of unloaded leg posture in cockroach and leg swing in mouse, which have more rapid muscles. Cockroach and mouse motor control 
mirrored that found in stick insect. Furthermore, comparing motor control strategy across several animals with rapid muscles showed a graded, size-dependent transition in swing motor control strategy. These observations suggest that this transition is a scaling phenomenon, and that limb size is a major determinant of neural control strategy of unloaded limb posture and movement.

Preliminary reports of these data have appeared in abstract form (Guschlbauer et al., 2005; Blümel et al., 2007a,b).

\section{Materials and Methods}

Extracellular recordings of Carausius morosus muscle activity (EMGs). Techniques to record C. morosus muscle activity during walking are described in detail by Gruhn et al. (2006) (see Figs. 1, 4). In brief, adult female C. morosus from the laboratory's (Universität zu Köln) colony that showed robust responses to handling were glued (ProTempII; 3M ESPE) ventral side down to a balsa rod, and all but the middle legs were removed. Activity was recorded from the protractor and retractor coxae or flexor and extensor muscles by inserting fine wires into each muscle and a reference electrode into the abdomen. EMGs were amplified 100fold with a preamplifier (electronics workshop, Zoologisches Institut, Köln), bandpass filtered ( $100 \mathrm{~Hz}$ to $2 \mathrm{kHz}$ ), further amplified 20-fold, and transferred to a computer using a Micro 1401 II data acquisition system and Spike 2 (version 5.05) software (both Cambridge Electronic Design).

Stance and swing were detected as follows. Electrode cream (GE Medical Systems) was applied to the tibia cuticle, and a portion of a copper wire from which the insulation had been removed was wrapped around the tibia. The other end of the wire was connected to a differential amplifier (electronics workshop, Zoologisches Institut, Köln). The animals were then situated so that when they were not walking, their feet touched a metal plate coated with an electrically conductive, slippery $(5 \% \mathrm{NaCl}$, $95 \%$ glycerin) solution, and low-voltage square-wave pulses were applied to the plate using a pulse generator (model MS501, electronics workshop, Zoologisches Institut, Köln). During walking (induced by touching the animal's abdomen) (Bässler and Wegner, 1983), the electric circuit only became closed, and the square-wave pulses were thus detectable by the differential amplifier, when the leg touched the plate (stance). Swing phase start and end were defined by setting thresholds in the tarsal contact trace. Steps without clearly alternating antagonistic muscle activity were excluded from analysis.

The effect of gravity on leg motor nerve activity (see Fig. 1) was determined by lifting the animals from the plate so that the legs were not in contact with a substrate and manually rotating the balsa rod to which the animals were glued to bring the animals to different orientations relative to gravity. Deafferentation and efferentation of the mesothoracic leg (protractor and retractor experiments) on one side of the animal were achieved by making a small incision on the ventral side of the animal and cutting all nerves on one side of the mesothoracic ganglion with fine scissors. The completeness of the procedure was confirmed by failure to elicit reflex responses in the leg in question.

Measuring isolated stick insect leg rest femur-tibia and cockroach joint angles. Stick insects were induced to autotomize a middle leg (see Figs. 2, 5). C. morosus leg flexion axons can spontaneously generate action potentials for a considerable time after leg autotomy (Schmidt and Grund, 2003). However, the movements these spikes induce are visually apparent, and all isolated leg experiments were performed after they had ceased (5-10 min post autotomy). The leg was then mounted in a stand under a tripod-fixed Fujifilm FinePix S602 Zoom camera, and the femur-tibia joint alternately was maximally flexed (to $20-30^{\circ}$ ) and extended (to $180^{\circ}$ ) by hand, and joint return angles were photographed. No limb was used $>30 \mathrm{~min}$; control experiments showed that robust return movements continued at least an hour after autotomy. Exactly analogous procedures were used in examining Periplaneta americana isolated leg femur-tibia joint passive properties, except that the leg was removed by cutting through the thorax-coxa joint and an Olympus E-330 camera was used. C. morosus leg flexor and extensor muscles were ablated by inserting a hot needle into the femur up to (but not into) the femur-tibia joint and moving it along the interior walls of the femur. Flexions and extensions were then performed again as above. In all cases the returns were photographed $5 \mathrm{~s}$ after the flexion or extension. Data on the time course of the returns were not obtained, but visual observations indicate that return velocity was highest at return beginning and decreased as the joint equilibrium angle was approached. Pictures were transferred to a personal computer and joint angles were measured in Canvas (ACD Systems). Data were analyzed and plotted in KaleidaGraph (Synergy Software) and final figures were prepared in Canvas for these and all other data presented here.

Passive muscle force measurements. For detailed methods of measuring C. morosus leg muscle properties (see Fig. 3), see Guschlbauer et al. (2007). In brief, the thorax was opened by cutting along the animal's longitudinal axis, and gut and fat tissue was removed. Nerves $n l 3$ (for the extensor tibiae) or $n c r$ [for the flexor tibiae; nomenclature according to Marquardt (1940)] were either crushed or cut to prevent motor neuron activity from reaching the leg muscles. Animals were pinned ventral side down on a balsa wood platform with all legs except the right middle cut at mid-coxa. The femur was embedded in dental cement (two-component glue, ProTempII; 3M ESPE), opened distally, and carefully dissected to access the extensor or flexor tibiae tendon. In both cases the tendon was cut with the femur-tibia joint at $90^{\circ}$ (the muscle reference length) and perforated with a hook-shaped insect pin that connected the muscle to the lever arm of an Aurora 300 B dual-mode lever system (Aurora Scientific Inc.). Muscles were stretched with SPIKE2 (Cambridge Electronic Design) Sequencer-generated ramps, and passive muscle forces were determined after the initial force response had decayed to approximately steady state. Drops of stick insect saline (in mM: $178.54 \mathrm{NaCl}, 10 \mathrm{HEPES}$, $7.51 \mathrm{CaCl}_{2} \cdot 2 \mathrm{H}_{2} \mathrm{O}, 17.61 \mathrm{KCl}, 25 \mathrm{MgCl}_{2} \cdot 6 \mathrm{H}_{2} \mathrm{O}, \mathrm{pH}$ 7.2) (Weidler and Diecke, 1969) were applied to the distal muscle end throughout the experiment.

Extracellular recordings of mouse muscle activity. EMG recordings during walking on a treadmill (speed, $0.2 \mathrm{~m} / \mathrm{s}$ ) were made (Columbia University, New York, NY) from left hind leg hip (iliopsoas) and ankle (tibialis anterior) flexor muscles in three male and two female adult (50- to 90-d-old) mice (see Fig. 6). Data were recorded to a computer using a Power1401 data acquisition system and Spike 2 (version 6.02) software. EMG electrode fabrication and implantation are described in detail by Akay et al. (2006) and Pearson et al. (2005). Leg movement data were obtained by attaching custom-made cone-shaped reflective markers to the skin of the left hind leg above the level of the anterior end of the iliac crest, hip, knee, ankle, the fifth toe joint, and the tip of the fourth toe (Pearson et al., 2005; Akay et al., 2006) and recording marker movement using a high-speed (250 frames/s) Fastcam PCI R2 video camera (Photron USA). Video data were analyzed using Peak Motus 8.2 (Peak Performance Technologies Inc.) motion analysis software. Swing onset and offset were defined as the times when the toe marker began moving forward or backward, respectively. Kinematic and EMG data were synchronized by matching a light-emitting diode flash in the video files with a simultaneous voltage step in the EMG recordings (Pearson et al., 2005; Akay et al., 2006). All data were obtained $2 \mathrm{~d}$ after the implantation surgery.

Calculating mean EMG activities and phase normalization to cycle period. Mean EMG activities (see Figs. 4, 6) were calculated in Spike 2 by marking swing end in each cycle from either the tarsus or toe movement data and using a built-in function to perform the averages (see Figs. 4, 6, 7). The data shown are mean data (Fig.4, 54 steps; Fig. 6, 27 steps) from the same animals for which the EMG data in the figures were obtained. Data from other animals ( $N=4$ for $C$. morosus, $N=5$ for mouse) were similar and, in particular, in all cases showed swing motor neuron activity that continued throughout swing duration. For the mouse, phase normalization (see Fig. 7) was performed by dividing each step cycle into 50 subdivisions. The rectified and lowpass-filtered EMG traces in each subdivision of the 27 steps were averaged to obtain mean EMG values in each time subdivision, and hence a mean EMG trace versus time. The time value of each subdivision was then divided by average step cycle period to transform the time values to phase.

Because of large step-to-step variation in cycle period in stick insect walking, phase normalization for C. morosus was performed individually for each step using GNU Octave as follows. Step cycle period was first 

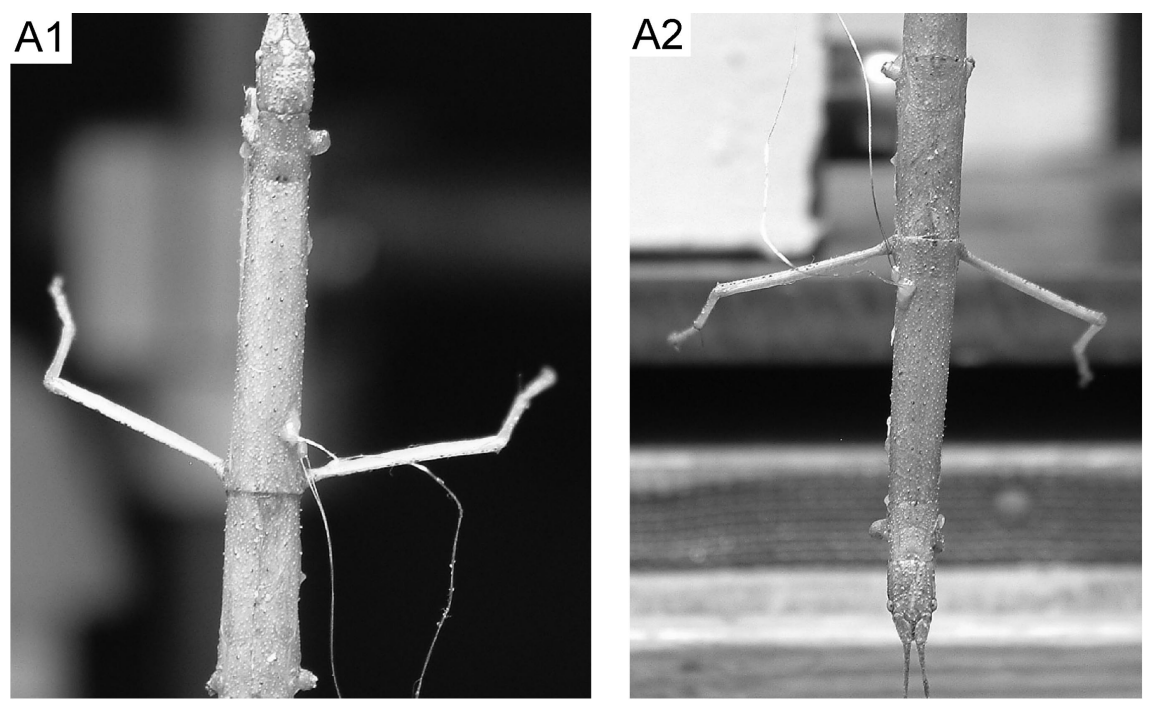

A3 Head up $\quad$ Rotation
Pro
EMG
Ret
EMG

B
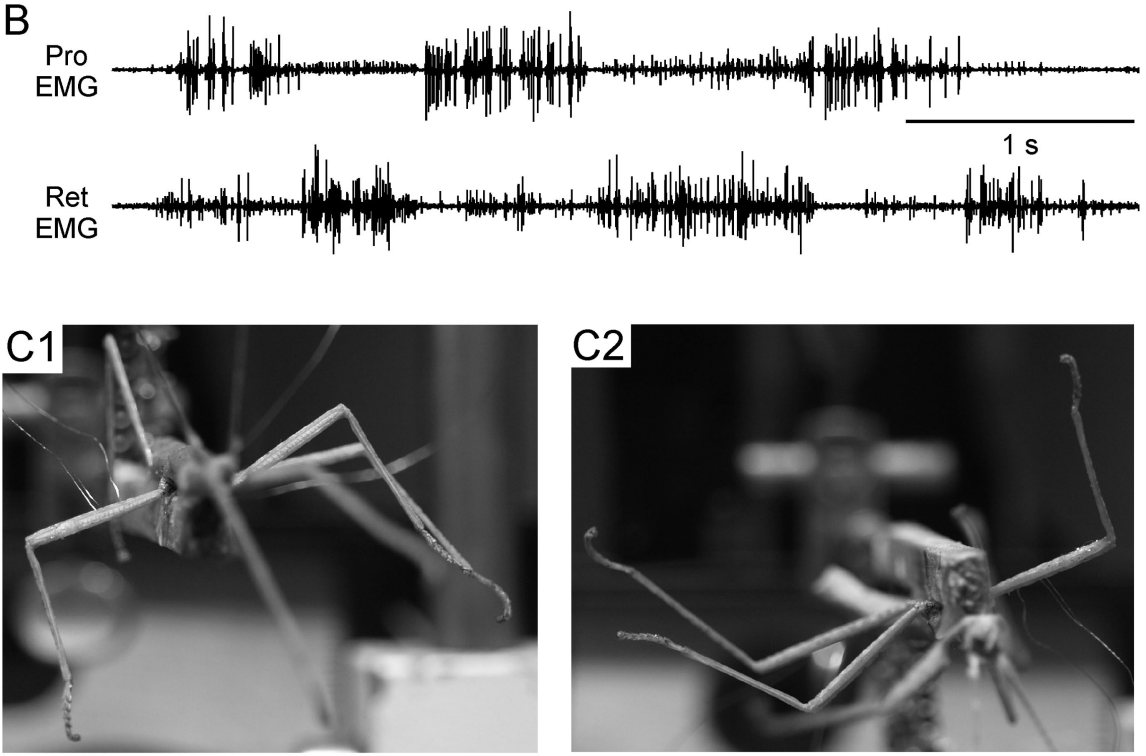

C3

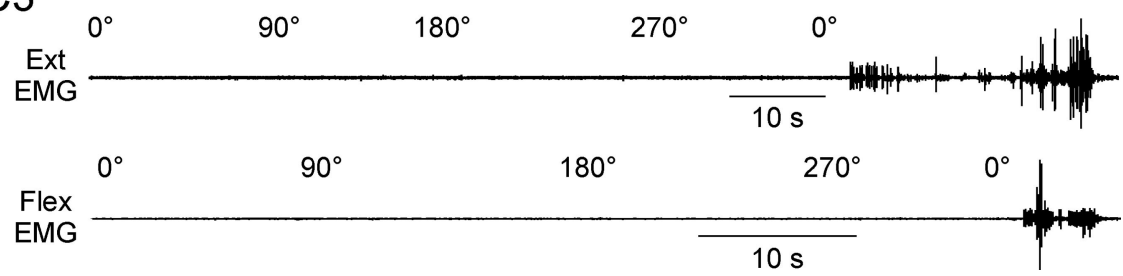

Figure 1. C. morosus legs assume constant, gravity-independent postures in the absence of leg muscle nerve activity. $\boldsymbol{A}$, Photographs of an animal in head-up (A1) and head-down (A2) positions with the long axis of the body positioned parallel to gravity (i.e., in $\boldsymbol{A} \mathbf{1}$ the animal is oriented similar to a standing human). The left side of the animal was opened ventrally and all nerves innervating the middle leg muscles, including the protractor and retractor coxae muscles, were severed. The innervations of the muscles on the right side were left intact and EMGs recorded from the protractor and retractor muscles. Both legs remained almost perpendicular to the body's long axis regardless of animal position. Simultaneous recordings (A3) of activity in the protractor and retractor muscles, which control leg position in this plane, showed that maintenance of these postures was not associated with measurable muscle activity, which was absent at all head orientations and during rotations between orientations. $B$, Recordings of protractor and retractor activity during walking induced by touching the animal showed that the recording electrodes were functioning. C, Photographs of an animal ventral (C) and dorsal (C2) side down. Femur-tibia joint (the femur is defined as beginning at each swing beginning. Each step's rectified EMG was then resampled at $10 \mathrm{kHz}$. A step with a cycle period of $1.234 \mathrm{~s}$ would thus have 12,340 EMG values, each associated with a time value of $0 \mathrm{~s}, 0.0001 \mathrm{~s}, 0.0002 \mathrm{~s}$ etc. We chose to build the phase plots using 200 points each, and hence wanted the EMG value at phases of $0,0.005,0.01$, etc. The task was thus to identify which samples in the resampled EMG corresponded most closely to these phase values. This was determined by multiplying the total number of EMG values by the desired phase. For example, for phase 0.005 , the desired sample number would be $0.005 \times 12,340=$ 61.7. Because there were only integer sample numbers, an integer function that truncated the decimal portion was used to transform the decimal values into integers. Thus, in the case at hand, the EMG value associated with sample 61 was used as the EMG value at phase 0.005. Each sample number's EMG value was then averaged across the 54 steps.

\section{Results}

The work reported here was triggered by the observation that at least one C. morosus leg muscle contracts and relaxes very slowly (Hooper et al., 2007a,b). These data suggested that neural control of this muscle in posture and walking might differ from that in systems with more rapid muscles. Simultaneously with work investigating this issue, we were independently performing experiments defining extensor muscle properties in greater detail (Guschlbauer et al., 2007). As we obtained the C. morosus data, it became clear that work in other species (cockroach and mouse) would also be necessary. Thus, the work on these four projects was not performed in a species-specific order, but instead was performed incrementally, moving back and forth between species and projects as our understanding advanced. Consequently, we do not present the data in the order in which the experiments were performed, but instead organize them logically: neural control of posture in C. morosus, neural control of swing phase in C. morosus, and comparison of $C$. morosus data and data from other animals.

\section{$\leftarrow$}

the portion of the leg lying relatively horizontally and the tibia the portion lying vertically, pointing downward, in (1) angle did not change when animal position relative to gravity was changed. Recordings from the flexor and extensor muscles (which control this joint) showed that this maintenance of femur-tibia joint angle was not associated with measurable muscle activity (C3). The last portions of the recordings were the activity that occurred when the animal was induced to walk, and show that the EMG electrodes were functioning. The recordings in $\mathbf{C}$ were from the same animal but are not simultaneous (first the extensor muscle was recorded from and the animal rotated $360^{\circ}$ and then the flexor was recorded from and the animal again rotated $360^{\circ}$ ). 


\section{Neural control of posture in C. morosus}

When intact $C$. morosus were glued to a wooden dowel and the animal was lifted into the air so that its legs were not in contact with a substrate, the legs assumed characteristic postures, with the femurs positioned perpendicular to the body's long axis (Fig. $1 A 1$, right leg; for left leg, see below). These postures were not altered by changing the animal's position relative to gravity (in Fig. $1 \mathrm{~A} 1$ the animal was head up with the body's long axis parallel to gravity, like a standing human, and in Fig. $1 \mathrm{~A} 2$ the animal had been rotated $180^{\circ}$ so that the head pointed down, like a human suspended from her/his feet; these changes would be expected to alter femur position relative to the body's long axis if the direction of the gravity vector affected the angle of the thorax-coxa joint).

Maintaining perpendicular joint postures with human shoulders or hips (roughly equivalent to the thorax-coxa joint) would require continuous muscle activity to counteract gravity, and the pattern of muscle activation would change as the human was rotated heels over head. However, simultaneous recordings of protractor and retractor muscle activity (the muscles responsible for controlling the thorax-coxa joint) showed that in C. morosus, there was no activity in these muscles regardless of the animal's position relative to gravity. (Fig. $1 A 3$ shows activity in these muscles in the right leg with the body in the original head-up position, during counterclockwise rotation of the animal to the head-down position, and further counterclockwise rotation to return to the head-up position; Fig. $1 B$ shows that inducing the animal to walk resulted in robust protractor and retractor activity, and thus that the EMG electrodes were functioning properly.) One explanation for these data was that muscle activity was occurring in these experiments, but the amplitude of the units being activated was too small to be recorded by the EMG electrodes. However, deafferented and de-efferented legs (the left leg in Fig. $1 A$ ) continued to assume constant, gravity-independent postures. Although these data do not prove that small-amplitude units were not active during these experiments, they do show that this activity is not necessary for the legs to assume and maintain these postures.

These constant, gravity-independent postures occurred not only at the thorax-coxa joint, but also at a more distal joint, the femur-tibia joint (roughly equivalent to human elbow or knee joints). When the body was rotated around the body's long axis, the femur-tibia joint angle did not change (rotation about this axis would be expected to alter the femur-tibia joint angle if the direction of the gravity vector affected the angle of this joint) (Fig. $1 C 1, C 2)$. The femur-tibia joint is controlled by the extensor and flexor muscles, and recordings from these muscles showed that this maintenance of femur-tibia joint angle, regardless of position relative to gravity, was not associated with measurable activity in the muscles (Fig. 1C3).

We have well developed techniques for working with the extensor and flexor muscles (Guschlbauer et al., 2007; Hooper et al., 2006, 2007a,b) and, therefore, used this joint to study the mechanisms underlying the constant, gravity-independent leg postures. We first verified that the constant, gravity-independent postures of this joint did not depend on neural activity by removing the leg from the animal. Isolated leg femur-tibia joints assumed a constant angle of $\sim 90^{\circ}$, and rotating the femur so that the tibia had different orientations relative to gravity had no effect on this angle (data not shown). Moving the tibia showed that after either flexion (Fig. 2A1) or extension (Fig. 2A2), the tibia returned to femur-tibia angles between $75^{\circ}$ and $90^{\circ}$ (Fig. $2 \mathrm{~A} 3$, grouped data).

These constant, gravity-independent, passively determined joint angles could arise from at least two mechanisms. The first is
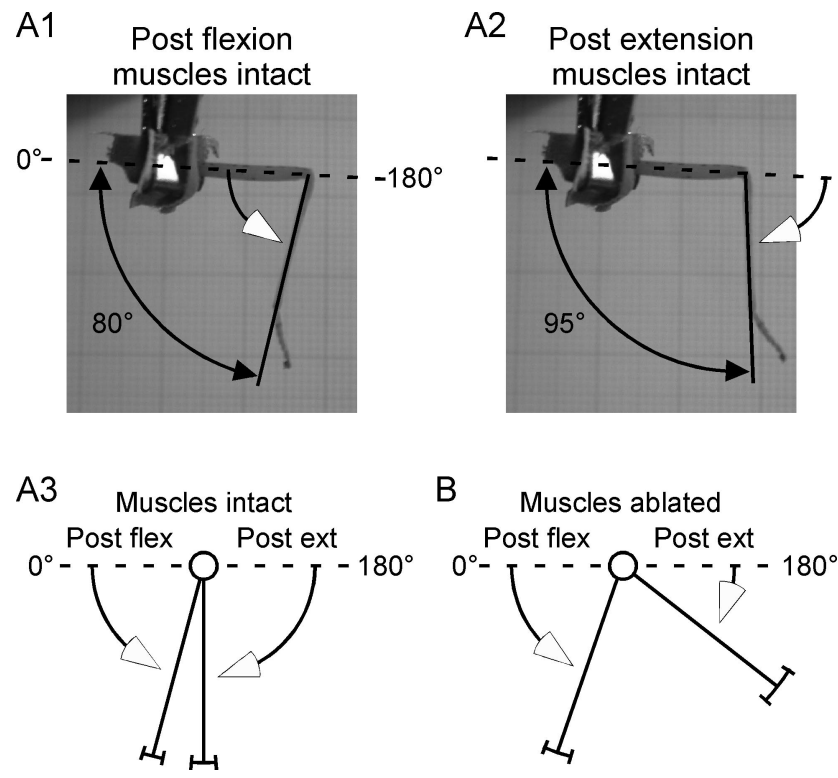

Figure 2. Isolated C. morosus femur-tibia joints drive to constant angles after flexion or extension. Photographs of $C$. morosus returns after flexion (A1) and extension (A2). Lines with open arrows indicate direction of leg movement during passive returns. $\boldsymbol{A} 3$, Mean data. $\boldsymbol{B}$, Mean data after extensor and flexor muscle ablation. Means and SDs were (muscles intact) postextension, $90 \pm 8^{\circ}$, postflexion, $75 \pm 6^{\circ}$ (muscles ablated), postextension, $142 \pm 12^{\circ}$, postflexion, $71 \pm 9^{\circ} . N=6$. Intact and ablated postextension returns differed at $p<0.0001$; intact and ablated postflexion returns did not differ ( $p=0.99$ ) (repeated measure Student's $t$ test).

the cuticular structures of the joints having a preferred joint angle. This mechanism could arise because insect joint cuticular tissues are less flexible than, for instance, human skin and connective tissues. Compression of $C$. morosus joint interior cuticular tissues and stretch of joint exterior cuticular tissues, as would occur with joint flexion, and stretch of interior cuticular tissues and compression of exterior cuticular tissues, as would occur with joint extension, could therefore generate forces that help restore joint angle after perturbations from the rest angle. We tested the role of cuticular structures by ablating the extensor and flexor muscles (Fig. 2 B). Muscle ablation little altered postflexion returns, suggesting that cuticle-generated forces play a major role in restoring joint angle after flexion. However, muscle ablation strongly reduced postextension returns, suggesting that cuticlegenerated forces play a minor role in restoring joint angle after extension. In one experiment in which the muscles were cut from their attachment points to the cuticle (the apodemes), as opposed to being ablated, similar changes in returns were observed. In this experiment we also tested the role of the cuticular tissue directly by removing the cuticle from the interior and exterior of the joint after the muscles had been cut from the apodemes, leaving only the medial joint cuticle intact. In this case the joint appeared to no longer have a preferred angle to which it returned, instead remaining at whatever angle it was placed.

A second mechanism for these constant rest joint angles arises from muscles being spring-like entities that generate passive restoring forces when stretched beyond their rest length. Muscles could thus give rise to constant rest joint angles if the flexor and extensor muscles generated approximately equal passive forces at the rest angles, and net restoring forces at other angles. Experiments on isolated flexor and extensor muscles (Fig. 3) showed that the muscles generated equal forces at angles between $70^{\circ}$ and $90^{\circ}$, in good agreement with the data from intact legs. For such forces to result in gravity-independent rest joint angles, the net 


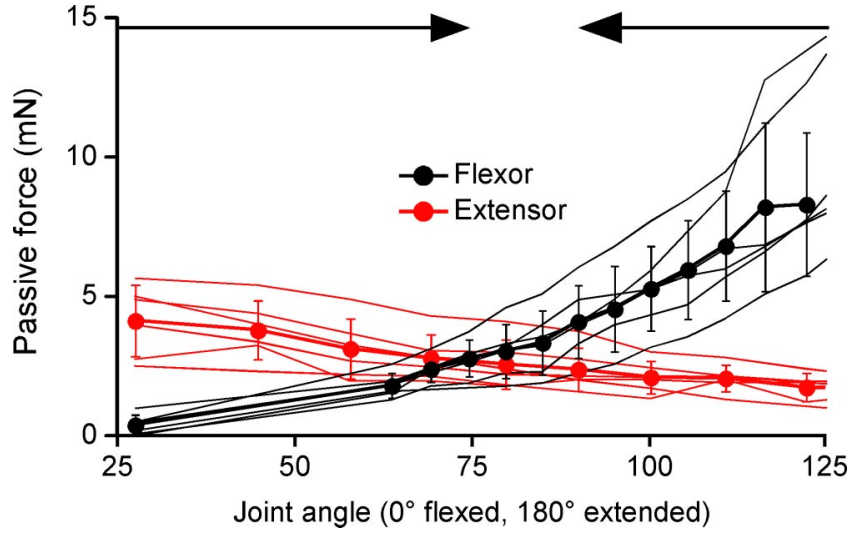

Figure 3. Isolated stick insect femur-tibia joint muscles develop large passive forces that are approximately equal at the rest joint angles observed in intact legs. Flexor (black) and extensor (red) static passive length-tension curves ( $N=6$ for each muscle) overlap at the same angle range that intact legs return to after perturbation (Fig. $2 \mathrm{A3}$ ). Thin lines are data from individual muscles, thick lines with closed circles are mean data, error bars are SDs. Joint angles were calculated from stretched muscle lengths using moment arms measured in Guschlbauer et al. (2007). Arrows at top of panel show the angles ( $75^{\circ}$ and $90^{\circ}$, respectively) that legs with intact muscles drove to after flexion and extension.

difference between flexor and extensor muscle passive forces at other angles would need to be large compared with leg weight. The parts of the limb that these muscles move, the tibia and tarsus, have a combined mass of $3.3 \pm 0.2 \mathrm{mg}(\mathrm{SD}, N=5)$, on which the force of gravity is $0.03 \mathrm{mN}$. The difference in flexor and extensor passive force as the joint was perturbed could be as large as $6 \mathrm{mN}$ (Fig. $3,125^{\circ}$ joint angle), and was $>1 \mathrm{mN}$ for all angles outside the $70-90^{\circ}$ range. Muscle-derived net restoring forces were thus 30 - to 200 -fold greater than the force of gravity on the leg segments in question, clearly sufficient to contribute to gravity-independent joint positions.

\section{Neural control of swing phase in $C$. morosus}

We next measured protractor (swing) motor neuron firing during walking (Fig. 4). The upper three traces show raw and rectified protractor EMG data and tarsus contact (gray shading marks swing phase) for eight steps, and the bottom plot shows mean data from 54 steps (gray shading again indicates swing duration). Protractor motor neurons began to fire shortly before full tarsus liftoff (horizontal upper portion of tarsus contact trace) and continued to fire throughout the entirety of swing.

\section{Comparison of $C$. morosus data to those from other animals}

The work examining neural control mechanisms in C. morosus was motivated by the presence of at least one very slow leg muscle in this animal (Hooper et al., 2007a,b). C. morosus also moves very slowly, and freezes as a protective mechanism when threatened (Bässler, 1972, 1983; Godden, 1974). Similar fixed joint rest angles, perhaps gravity-independent and likely attributable to an equilibrium point of agonist and antagonist passive forces, have also been seen in crustacea (Yox et al., 1982), which suggests that the data presented above were probably not limited to stick insects. Nonetheless, to ensure that the data in Figures 1 and 2 were not attributable to C. morosus' specialized behavior, we repeated the isolated leg experiments on an animal renowned for its locomotory speed and versatility, the cockroach, $P$. americana. These experiments showed that, despite the speed difference between the two species, $P$. americana isolated femur-tibia joints also had constant, gravity-independent rest positions to which they returned after perturbation (Fig. 5).

To further test whether the $C$. morosus data were the result of this animal's slow properties, we examined swing motor control in mouse hind leg (Fig. 6). The justification for performing these experiments was that, although mammals do have fast and slow skeletal muscle fibers, even the slowest of these are much faster than stick insect extensor and other slow invertebrate nonspiking muscles, which can take hundreds to thousands of milliseconds to reach steady-state contraction levels in response to tonic motor neuron firing at physiological spike frequencies (Morris and Hooper, 1997; Hooper et al., 2007b). As such, if the slow properties of C. morosus muscles gave rise to unusual motor control strategies, these should be clearly shown by comparing motor control in C. morosus and animals, such as mammals, with much more rapidly contracting muscles. The top trace of Figure $6 \mathrm{~A}$ shows mouse hip flexor (swing) muscle raw EMG activity, the second, rectified and smoothed EMG activity, and the third, toe position. The gray shading again marks swing phase. Figure $6 B$ shows mean activity from 27 steps, with the gray shading showing swing duration. Mouse hip flexor activity slightly preceded swing beginning and, exactly as in C. morosus, continued throughout swing. Recordings from mouse ankle flexor muscles showed that these muscles were also active throughout the entirety of ankle flexion (data not shown).

These results suggested that the C. morosus data were unlikely attributable to this animal's slow properties. To gain insight into this issue, we compared mean C. morosus protractor and mouse hip flexor motor neuron activity during swing and stance to data from the literature for cat, human, and horse hip flexors (Fig. 7). The stick insect, mouse, and cat data differed markedly from the human and horse data, with the smaller animals having swing motor neuron activity that continued throughout swing and the larger ones having swing activity only at swing beginning. Swing motor neuron activity also continues throughout the entirety of swing in guineafowl (Gatesy, 1999), chick (Jacobson and Hollyday, 1982), and newt (Székely et al., 1969) legs and small (ankle) limb segments in humans (Prochazka et al., 1989; Halliday et al., 2003; Cappellini et al., 2006).

The data in Figure 7 are in the phase (normalized to cycle period) domain, and thus contain no information about cycle period, swing, or swing EMG activity durations. Examining actual durations, as well, is interesting for two reasons. First, in mouse, cat, human, and horse, the legs are beneath the body (as opposed to the sprawling posture of the stick insect) and thus their swings could be at least partially pendular, and hence governed by the relationship cycle period $=2 \pi \mathrm{V}$ limb length $/ g$. Second, such an analysis might reveal whether there is some simple relationship between swing motor neuron activity (EMG duration) and other motor pattern parameters (cycle period, swing duration) or limb length.

With respect to the first point, mouse, cat, human, and horse legs [using leg lengths of $5 \mathrm{~cm}$ (mouse), $15 \mathrm{~cm}$ (cat), $100 \mathrm{~cm}$ (human), and $150 \mathrm{~cm}$ (horse)] would have pendulum-alone swing durations (one-half of pendulum cycle period) of $200 \mathrm{~ms}$ (mouse), $400 \mathrm{~ms}$ (cat), $1000 \mathrm{~ms}$ (human), and $1200 \mathrm{~ms}$ (horse). Actual swing durations are $105 \mathrm{~ms}$ (mouse), $227 \mathrm{~ms}$ (cat), $325 \mathrm{~ms}$ (human), and $455 \mathrm{~ms}$ (horse). In all cases, swing motor neuron activity thus accelerates limb swing to faster velocities than those that would occur from simple pendulum dynamics alone. Figure $8 \mathrm{~A}$ plots swing durations in these animals versus leg length, and shows linear and square root fits to the data. The fits are equally good. These data thus cannot rule out that pendular dynamics 
play some role in swing in these limbs (the acceleration noted above that occurs during swing in these limbs is the reason for the value of " 37 " in the square root fit; with the units used in this figure, this parameter would be " 100 " if the limbs moved only as pendulums during swing).

With respect to the second point, swing EMG durations are $208 \mathrm{~ms}$ (stick insect), $116 \mathrm{~ms}$ (mouse), $227 \mathrm{~ms}$ (cat), $204 \mathrm{~ms}$ (human), and $110 \mathrm{~ms}$ (horse). Despite the monotonic increase in swing duration as limb length increases (Fig. $8 \mathrm{~A}$ ), plotting swing EMG duration versus limb length shows no monotonic relationship (Fig. $8 B$; note that in this plot the stick insect data have been included, but that the nonmonotonic relationship remains even without the stick insect data). Swing EMG duration shows a similar nonmonotonic dependence when plotted against swing duration or step cycle period (stick insect, $410 \mathrm{~ms}$; mouse, $290 \mathrm{~ms}$; cat, $700 \mathrm{~ms}$; human, $1000 \mathrm{~ms}$; horse, $1400 \mathrm{~ms}$ ) (data not shown). Figure 7 shows that swing EMG activity occupies an increasing proportion of swing duration as animal size decreases. Figure $8 C$ quantitates this relationship by plotting swing EMG duration divided by swing duration versus limb length, and shows that these parameters are linearly related. This analysis shows that although swing duration increases monotonically with leg length, swing EMG duration shows no simple dependence on limb length. However, the percentage of swing duration that swing motor neurons fire depends linearly on limb length, decreasing as limb length increases.

We present in the Discussion a general hypothesis for why the duration of swing muscle activation should occupy an increasingly large proportion of swing duration as limb length decreases. With respect to the data specifically shown in Figure 7, however, a reason for the different swing motor neuron activation durations in stick insect and humans can be understood by using the data presented in Figure 3 for passive stick insect muscle forces and data from human lower leg to calculate (Appendix) how quickly passive muscle force caused by antagonist (stance) muscle stretch would stop leg swing in the two animals if swing motor neurons were to stop firing. These calculations show that human lower leg velocity would decrease because of antagonist muscle stretch only $63 \%$ in $0.8 \mathrm{~s}$, whereas in C. morosus muscle passive forces would completely stop tibia/tarsus momentumbased swing in $0.09 \mathrm{~ms}$. The magnitude of this difference can be appreciated by noting that, if protractor motor neurons stopped firing at any time, stick insect limb movement would cease in less time than the width of the dashed lines in Figure 7 marking swing-stance transitions. Alternatively, without the gluteus maximus activity that slows human leg movement at the end of swing (Lieberman et al., 2006), human swing would decrease only $63 \%$ in a time $25 \%$ longer than the entire time shown in the figure. $C$. morosus swing motor neuron activity must therefore continue window duration.
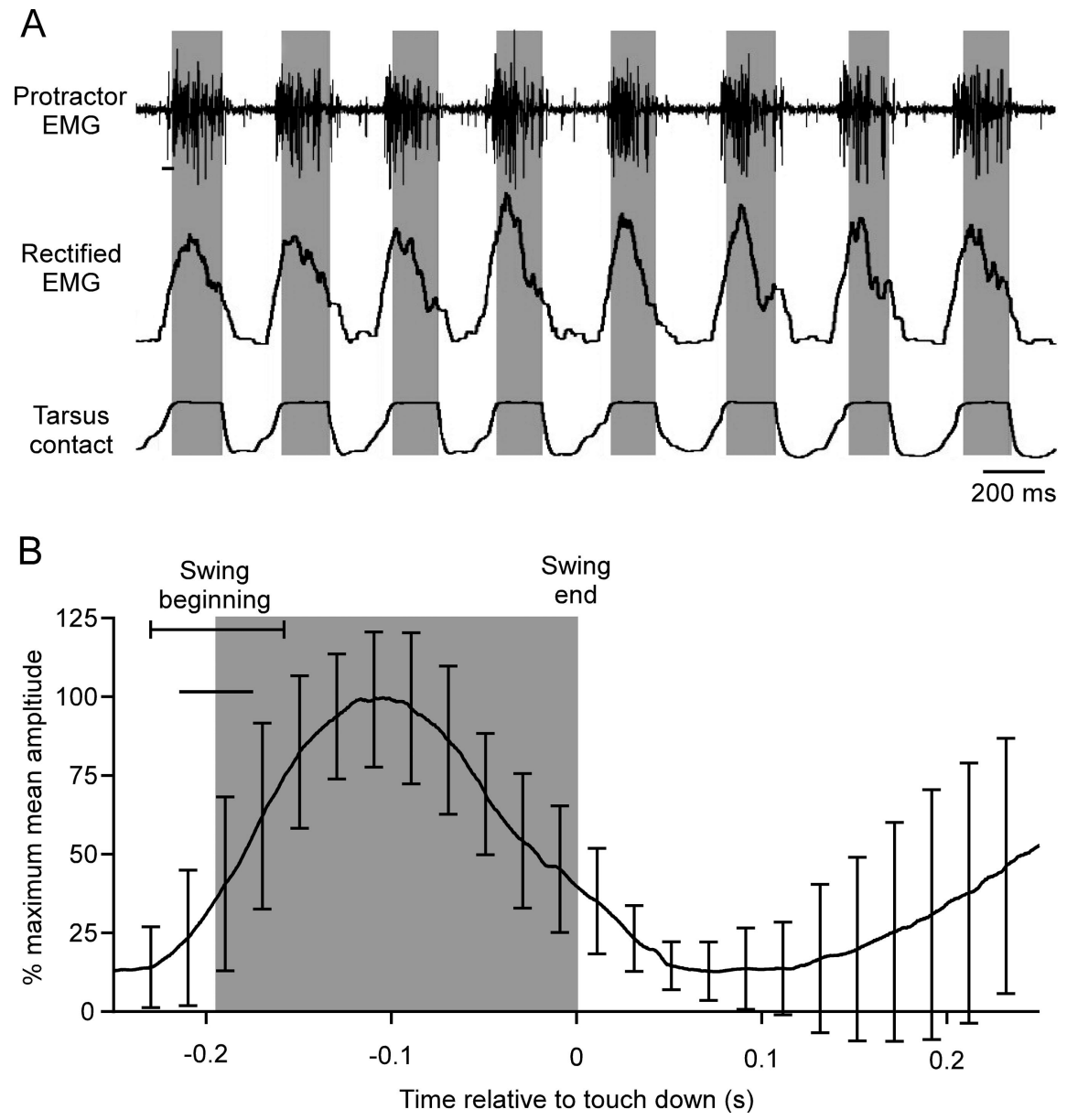

Figure 4. C. morosus protractor (swing) motor neuron activity continues throughout the entirety of swing. $\boldsymbol{A}$, EMG recordings of middle leg protractor coxae (Protractor) activity (top trace), rectified and smoothed ( $\tau=0.02 \mathrm{~s}$ ) EMGs (middle trace), and rect (third trace) while animal stepped on a slippery surface (Gruhn et al., 2006). Gray shadings indicate swing duration. The rectified EMG begins to rise before the EMG spikes because of the $20 \mathrm{~ms}$ smoothing window (horizontal line under (race). Tarsus contact trace shows graded onset and offset because of changing tarsus area in contact with the using swing end as time 0 . Gray shading indicates swing duration. Horizontal line under swing beginning SD line is EMG smoothing

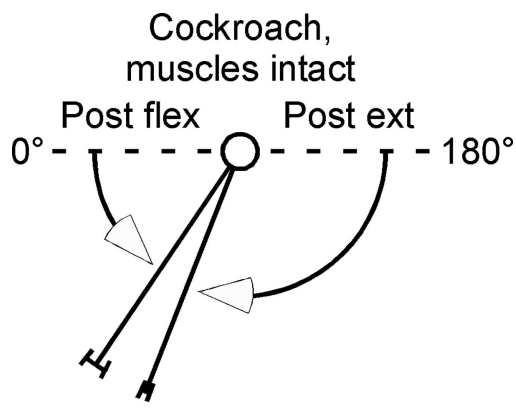

Figure 5. Cockroach femur-tibia joints drive to constant angles after flexion or extension. Figure conventions same as in Figure 2A3. Means and SDs were: postextension, $68 \pm 3^{\circ}$; postflexion, $56 \pm 6^{\circ}(N=3)$.

throughout swing because otherwise leg swing would instantaneously end, whereas in humans swing motor neuron activity can cease shortly after the initial acceleration of the leg because leg momentum can finish the swing movement.

In all animals in Figure 7 there is also swing motor neuron activity late in stance. In stick insect this early firing possibly 

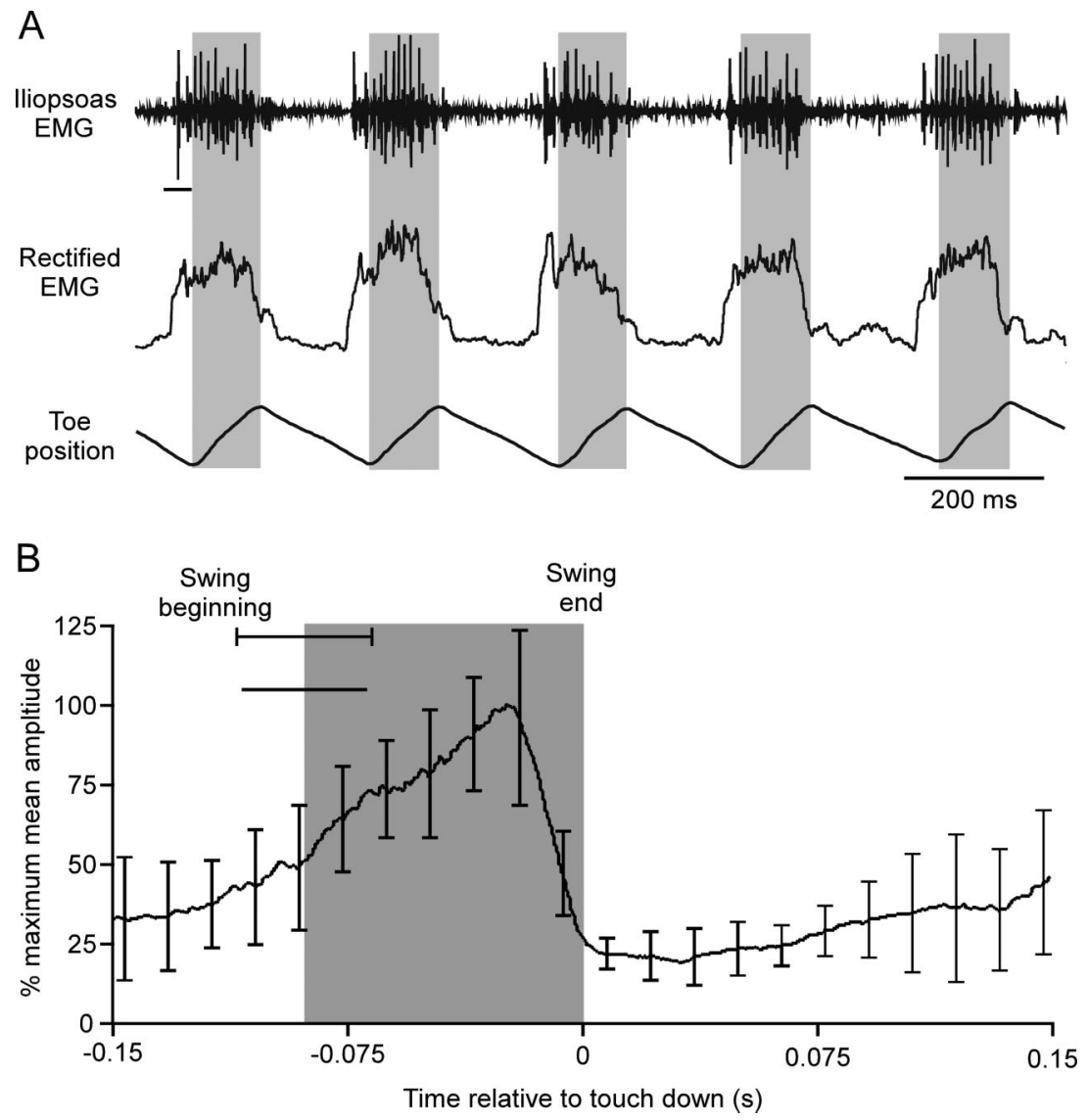

Figure 6. Mouse hip flexor (iliopsoas) activity begins before swing and continues throughout the entirety of swing. A, EMG recordings of left hind leg iliopsoas activity (top trace), rectified and smoothed EMGs (middle trace), and record of toe movement (third trace) while animal stepped on a treadmill. Gray shadings indicate swing phase. The rectified EMG begins to rise before the EMG spikes because of the $20 \mathrm{~ms}$ smoothing window (horizontal line under first spike in top trace). $\boldsymbol{B}$, Mean protractor EMG activity from one animal (27 steps, error bars are SD) averaged using swing end as time 0 . Gray shading indicates swing duration. Horizontal line under swing beginning SD line is EMG smoothing window duration.

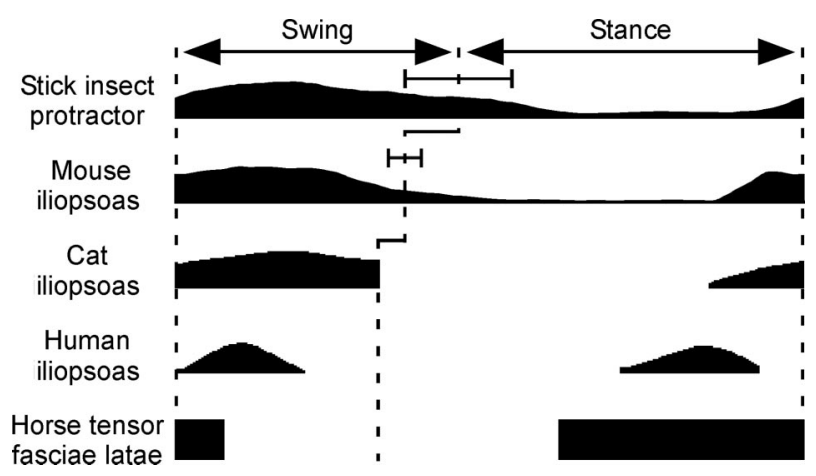

Figure7. Comparison of C. morosus, mouse, cat, human, and horse (horse data are themean of the activities observed during walk, trot, and cantor) swing motor neuron activity. C. morosus, mouse, and cat swing motor neurons are active throughout swing, human and horse swing motor neurons are active only at swing beginning. See Results for discussion of stance phase activities. For the horse data, the rectangles show only when swing motor neurons are active, not the amplitude of the activity; for the other traces, the varying heights of the traces show how the activity's amplitude varied in the step cycle. Cat, human, and horse data modified from Prochazka et al. (1989) and Tokuriki and Aoki (1995). Error bars on C. morosus and mouse data are SDs.

occurs because the protractor muscle, similar to the extensor (Guschlbauer et al., 2005, 2007; Hooper et al., 2007a,b), only slowly relaxes, which might result in insufficiently rapid swings if the extensor muscle were not "precontracted" before swing be- ginning. Although mouse and cat muscles contract much faster than do stick insect muscles, the timing of the early swing motor neuron activity (just before swing beginning) in these animals nonetheless suggests that it may serve a similar purpose in them. The motor neuron burst in the middle of stance in humans, ending as it does well before swing beginning, is likely attributable to the muscle in question being bifunctional, and serving as a hip flexor during swing (Hamilton, 1972; Warwick and Williams, 1980; Moore, 1983) but a lumbar spine flexor (Hamilton, 1972; Woodburne and Burkel, 1988) or stabilizer (Nachemson, 1966, 1968; Crisco and Panjabi, 1990; Santaguida and McGill, 1995) or even power muscle (Gracovetsky et al., 1986) during stance. The extent to which the stance phase activity in horse, which begins in the middle of swing and continues without stopping until approximately one-third of the way into swing, is attributable to similar bifunctionality versus preparing for leg swing is unclear.

Together, these data suggest that the different motor control strategies seen in the small and large animals result from the different sizes of the limbs being moved (see Discussion), not whether the muscles are slow or fast. Nonetheless, the insect data may have relevance to two characteristics often seen in invertebrate slow muscle, the presence of high resting muscle tension (tonus) (Hoyle, 1978) and of inhibitory motor neurons (Pearson and Bergman, 1969; Pearson and Fourtner, 1973; Hale and Burrows, 1985; Rathmayer and Bevengut, 1986; Allgäuer and Honegger, 1993) and peripheral modulation of muscle properties (Evans and O'Shea, 1978; Cropper et al., 1987, 1990; Weiss et al., 1992; Evans et al., 1999), including increased relaxation rate. The hypothesis here is that, because in these limbs the joints will have gravity-independent rest positions and require continuous (excitatory) motor neuron activation to move in any case, (1) evolution may have taken advantage of this characteristic by increasing muscle resting tension to accentuate these properties and hence to have the limbs stably assume a particularly useful posture (e.g., appropriate for quiet standing) in the absence of motor neuron activity and (2) the common inhibitor motor neurons and neuromodulatory inputs may have evolved to decrease the interfering opposition of antagonistic muscles during active movement.

\section{Discussion}

Intact, unloaded C. morosus legs assumed constant, gravityindependent postures without any activity in leg motor nerves (Fig. 1). Isolated C. morosus and P. americana legs (Figs. 2, 5) assumed constant, gravity-independent postures and returned to them when perturbed. These postures in C. morosus were caused in part by the muscles controlling the joints generating equal passive forces at these angles (Figs. $2 \mathrm{~B}, 3$ ). Swing motor neurons fired throughout the entirety of swing in $C$. morosus, mouse, and cat but only at swing beginning in human and horse (Figs. 4, 6, 7). 
A

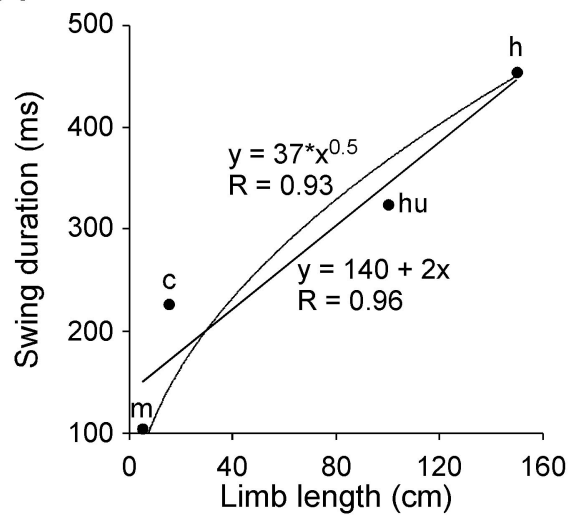

B

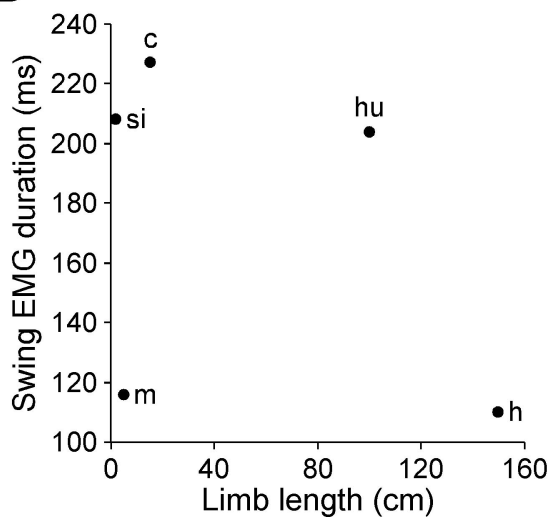

C

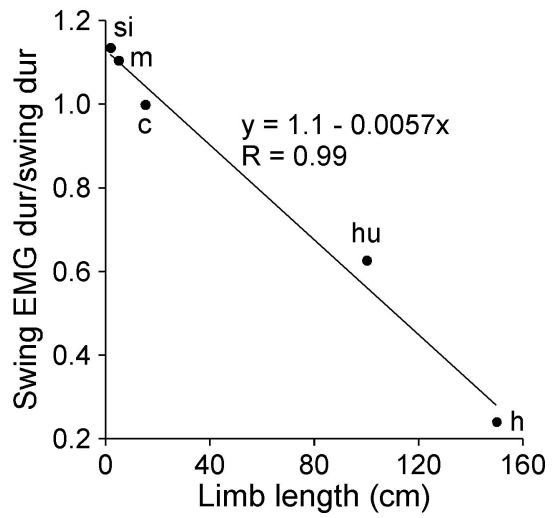

Figure 8. Plots of swing duration ( $\boldsymbol{A}$ ) (mouse, cat, human, and horse data), swing EMG duration ( $\boldsymbol{B}$ ) (all five species), and swing EMG duration divided by swing duration ( $\boldsymbol{C}$ (all five species) versus limb length. For mouse, cat, human, and horse limb the entire leg is indicated; for stick insect limb the tibia and tarsus are indicated. See Results for explanation. si (stick insect), $m$ (mouse), c (cat), hu (human), and $\mathrm{h}$ (horse) indicate which species the data in question are from.

\begin{abstract}
Gravity-independent rest positions and muscle passive force in other animals

Isolated Periplaneta, Blaberus, and Carcinus legs passively return to constant postures after perturbation (Fourtner, 1981; Yox et al., 1982; Dudek and Full, 2007). However, the Periplaneta and Carcinus leg positions relative to gravity were unspecified and the Blaberus legs were arranged horizontally "to remove the effect of gravity from the leg response" [Dudek and Full (2007), p 3211]. Whether these returns were gravity independent was thus unknown. Experiments on isolated Periplaneta legs showed that their returns are indeed gravity independent, and Carcinus passive muscle forces relative to leg mass are large enough that they should be as well. Multiple (ankle extensor, biceps femoris anterior, caudofemoralis, medial gastrocnemius, sartorius anterior, semitendinosus, tenuissimus) cat leg muscles develop passive forces (Grillner, 1972; Stephens et al., 1975; Brown et al., 1996) equal to the force of gravity on masses much larger $(0.8-4 \mathrm{~kg})$ than those of the limbs the muscles move, and these limbs should thus also have gravity-independent rest postures. Relaxed human fingers assume a " $\mathrm{C}$ "-shaped configuration regardless of hand position relative to gravity. These small limbs may thus also have gravity-independent rest postures.
\end{abstract}

\section{Use of gravity-independent rest positions in movement control}

At stance end, C. morosus' middle legs are retracted far behind the thorax-coxa joint rest positions shown in Figure 1 (Wendler, 1964; Cruse and Bartling, 1995). One might therefore predict that C. morosus protractor motor neurons would not need fire at swing beginning because the initial portion of swing could occur from passive muscle forces alone. Protractor motor neuron activity nonetheless does occur in early swing (Fig. 4), and in this species all aspects of swing are thus actively driven. Other nervous systems, however, clearly take functional advantage of small limbs having gravity-independent rest positions. Locust leg movements against gravity, presumably passive returns to gravity-independent rest angles, can occur without motor neuron activity (Berkowitz and Laurent, 1996; Zakotnik et al., 2006; Page et al., 2008). Passive forces slow leg velocity during swing phase in turkey (Roberts et al., 1997). When extensor motor nerves in the related stick insect Cuniculina impigra are cut, extensor muscle passive force increases over several days (Bässler et al., 2007). This change shifts joint rest position to $180^{\circ}$, allowing the animals to make extension and flexion movements by activating the flexor muscle alone. A similar situation exists in the cockroach trochanter-femur joint, in which extension occurs solely because of passive joint properties (Watson et al., 2002).

\section{Does scaling explain the size dependence of gravity- independent joint posture and swing motor neuron firing differences?}

C. morosus, P. americana, Carcinus, and cat legs, and human ankles and fingers, either do or likely have gravity-independent rest positions, but human elbows, shoulders, knees, and hips do not. Stick insect, mouse, and cat swing motor neurons fire throughout swing, whereas human and horse hip swing motor neurons fire only at swing beginning. The dependence of these differences on limb size, and independence of whether the animals are vertebrate or invertebrate or the muscles are slow or fast, suggest the differences may result from a general scaling phenomenon.

This scaling would arise because muscle passive force varies with muscle cross-sectional area, but limb mass varies with limb volume. In large limbs, muscle passive forces would consequently be so small relative to limb mass that momentum and gravity would dominate limb mechanics: very heavy pendulums with very weak springs oscillate for long periods before stopping, and at rest hang essentially parallel to gravity. In small limbs, alternatively, muscle passive force would be so great relative to limb mass that gravity and momentum would be inconsequential: very light pendulums with very strong springs quickly cease to move, and have rest positions determined by spring forces, not gravity. For joints such as those in invertebrates in which joint tissues might exert restoring forces, analogous arguments apply because the force-generating tissue (the cuticle) is again fundamentally two-dimensional.

Figure 9 illustrates this idea. Figure $9 \mathrm{~A}$ shows a twodimensional schematic of a human leg with two attached muscles and 10-fold (mouse, very large insect legs) and 200-fold (Drosophila legs) reductions. In Figure $9 B$ the cylinders have been replaced with circles whose areas are proportional to cylinder mass, and the schematics normalized to limb mass (circle area). The ratio of muscle cross-sectional area to limb mass is much greater in Drosophila than in humans. Because muscle crosssection varies as size squared, but limb mass as size cubed, their ratio varies as $1 /$ size (Fig. 9 C, solid line). For cylindrical limbs this scaling effect is even greater, varying as size to the -2 nd power 

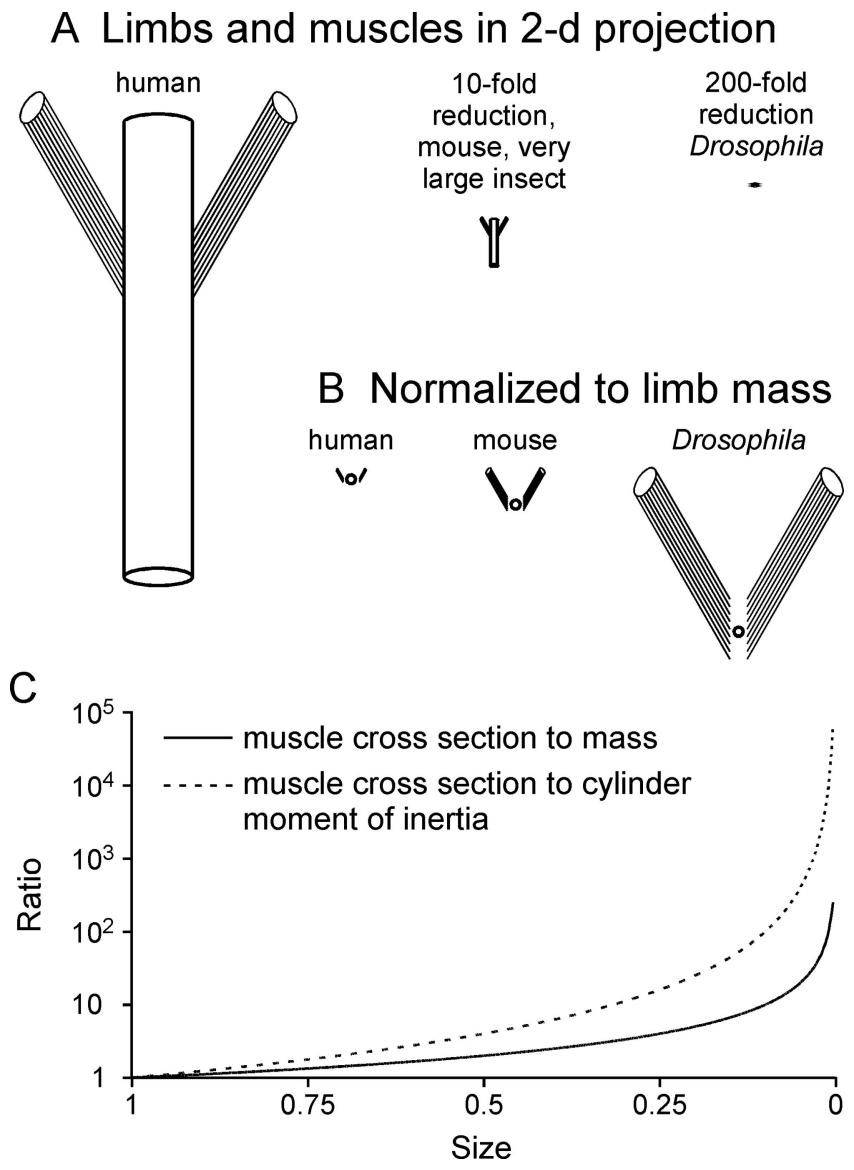

Figure 9. Muscles dominate limb-muscle systems at small limb sizes. Size scaling is accurate, animal identification is approximate.

(Fig. 9C, dashed line), because the relevant ratio is cross-section to moment of inertia, which varies as size to the 4 th power for cylinders.

Changes in other aspects of animal anatomy or physiology could of course alter these scaling effects. Size-dependent changes in moment arm length or muscle physiology (Nauen and Shadwick, 1999, 2001; Van Wassenbergh et al., 2007) could lessen the predicted shift of mass versus muscle in controlling limb rest posture and movement. Bird and mammal muscle cross-section varies as body mass raised to the 0.7 th to 0.9 th power (Alexander, 1977; Maloiy et al., 1979; Pollock and Shadwick, 1994), larger than the 0.67 expected for the proportional scaling in Figure 9. To create large grip strength, human fingers may be driven by larger muscles than scaling alone would predict. Nonetheless, given the several hundredfold size variation present in limbed animals and the data presented here, it is likely that scaling plays a major role in determining how nervous systems control limbs.

The ideas in Figure 9 are straightforward. We therefore extensively searched for them in the scaling, large and small vertebrate limb, invertebrate limb, energy and locomotion, inverted pendulum, large and insect-inspired robot, and general and textbook literatures (see supplemental material, available at www. jneurosci.org). In these literatures only one article specifically deals with muscle and limb scaling (Garcia et al., 2000). In this study, limb muscles were mimicked by a lumped single muscle rather than considering agonist and antagonist muscles separately. This work consequently could not predict two central issues: (1) that small limbs have gravity-independent rest positions (instead ascribing limb returns to being "mainly due to gravity") and (2) that muscle passive forces prevent small limbs from making momentum-based movements (instead predicting these movements would be powered by "short, quick [motor neuron] bursts").

Whether the scaling arguments made here are implicitly contained in this literature is impossible to disprove. However, we can state with certainty that they are never explicitly made, including in textbooks and lay treatments in which such explanation would be expected. Considerations of scaling effects are similarly lacking in explanations of biphasic agonist-antagonist and triphasic agonist-antagonist-agonist muscle activation patterns in limb movements. These motor neuron firing patterns make sense for only momentum-based movement control strategies, in which limb momentum induced by the initial agonist contraction must be diminished by subsequent antagonist activity. However, these authors never mention that these patterns are therefore expected to be used only to control large limbs, and that in small limbs agonist activation must instead continue throughout movement duration because, otherwise, antagonist passive force would prematurely stop limb movement.

This literature does extensively investigate the role of momentum and across-phase energy storage and release in locomotion (see supplemental material, available at www.jneurosci.org). Because this work studies whole body locomotion, not how nervous systems control movements of single unloaded limbs, the data presented here in no way contradict its conclusions. Indeed, small limbs having constant rest postures determined by muscle passive properties is completely consistent with much work in this field, as deflections from these postures in one movement phase would provide an excellent mechanism for storing energy for use in later phases.

\section{Evolutionary implications}

It is natural to assume that vertebrate motor neural networks and control strategies will resemble each other more than they do invertebrate ones. However, the data and ideas presented here suggest that limb size may be as important as phylogenetic position in determining motor control strategy. The neural control strategies of human fingers and ankles, and mouse, cat, and all invertebrate limbs may thus resemble each other more than any of them do human shoulder, elbow, hip, knee, and other largelimb control strategies. Furthermore, given that the first limbed animals were small, gravity-independent joint rest positions and non-momentum-based neural control strategies may represent the ur-state from which large-limb control strategies are a derived specialization.

\section{Appendix}

Calculating human knee oscillation decay time constant Calculating how quickly resistive forces slow human knee movement requires deriving the equations governing the movements of damped cylinders such as those in Figure 9. To avoid using moments of inertia and torques or needing to consider where on the cylinder the muscles attach, we replaced the cylinders with point-mass pendulums. The equation of motion of an undamped pendulum is $m \cdot l \cdot d^{2} \theta / d t^{2}=m \cdot g \cdot \sin \theta$, where $m$ and $l$ are pendulum mass and length, $\theta$ is the angle the pendulum makes to the vertical, and $g$ is the gravitational constant. Muscle and joint passive forces are $F_{\mathrm{r}}=-b \cdot l \cdot d \theta / d t-k \cdot l \cdot \Delta \theta$, where $l \cdot d \theta / d t$ is muscle stretch or joint velocity and $l \cdot \Delta \theta$ is displacement from muscle or joint rest position. Incorporating these 
terms, replacing $g / l$ with $\omega_{0}{ }^{2}$, and rearranging gives $d^{2} \theta / d t^{2}+$ $b / m \cdot d \theta / d t+k / m \cdot \Delta \theta+\omega_{0}^{2} \theta \sin \theta=0$.

This equation is not integrable. The equation of motion of a damped harmonic oscillator, $d^{2} \theta / d t^{2}+(b / m) d \theta / d t+\omega_{0}{ }^{2} \theta=0$, is an approximation valid for small $\theta$ that is integrable. Not including the displacement-dependent resistive forces is justified because we consider here a moving leg, and muscle velocitydependent forces are typically much greater than displacementdependent ones. For values of $b$ and $m\left(b / m<2 \omega_{0}\right)$ that allow oscillation, a solution to this equation is $\theta=e^{t / 2 \tau}(A \cos \gamma t+B \sin$ $\gamma t$, where $\tau=m / b, A$ and $B$ are initial condition-dependent constants, and $\gamma=\left(\omega_{0}{ }^{2}-b^{2} / 4 m\right)^{1 / 2}$. This function is a sinusoid of exponentially decreasing amplitude with time constant $\tau$. Measuring $\tau$ thus determines how quickly passive resistance alone decreases oscillation amplitude, and thus how quickly the oscillation ceases.

$\tau$ was calculated by measuring the amplitude decrease over the first oscillation cycle of a male adult knee after release of the foot from a raised position (zero initial velocity, movement due to gravity alone). This value is technically valid only for this particular set of conditions. For instance, if resistance to movement is greater at the higher velocities that occur during swing, this technique would underestimate how quickly passive properties slow the lower limb during walking. However, given the $\sim 9000$-fold difference between the human and stick insect values, any errors so introduced are unlikely to affect article conclusions.

\section{Calculating how quickly flexor muscle passive force would stop tibia swing}

Because stick insect legs do not oscillate after perturbation, the method explained above was not used. Flexor muscle passive force during $0.1 \mathrm{~s}, 0.5 \mathrm{~mm}$ linear ramp stretches mimicking those occurring during tibia extension were instead directly measured with an Aurora Scientific 300B dual-mode lever arm system. C. morosus muscles respond to stretch by producing an initial large force (the dynamic force) that then declines to a steady-state value (the static force) after ramp end (Guschlbauer et al., 2007). The forces shown in Figure 3 are the static forces, but because we are here examining the effect of changes of muscle force on a moving leg, we use here the average of the dynamic forces immediately at ramp end, $67 \pm 29 \mathrm{mN}(\mathrm{SD}, N=12)$. The flexor muscle works over a moment arm of $0.56 \mathrm{~mm}$ (Guschlbauer et al., 2007), and $67 \mathrm{mN}$ thus delivers a torque to the tibia of $38 \times 10^{-6} \mathrm{~N} / \mathrm{m}$. The tibia's moment of inertia is $0.32 \times 10^{-9} \mathrm{~kg} \mathrm{~m}^{2}$ (Guschlbauer et al., 2007), and thus flexor passive force results in an initial angular deceleration of $-117 \times 10^{3} \mathrm{rad} / \mathrm{s}^{2}$, or $-6.71 \times 10^{6 \%} / \mathrm{s}^{2}$. The highest angular velocity during swing is $11 \mathrm{rad} / \mathrm{s}\left(516^{\circ} / \mathrm{s}\right)$. Flexor passive force would thus stop tibia motion in $0.09 \mathrm{~ms}$ if the deceleration were linear. Flexor force production did not change within $0.5 \mathrm{~ms}$ after ramp end, and so this linear approximation was accepted.

\section{References}

Akay T, Acharya HJ, Fouad K, Pearson KG (2006) Behavioral and electromyographic characterization of mice lacking EphA4 receptors. J Neurophysiol 96:642-651.

Alexander RM (1977) Allometry of the limbs of antelopes (Bovidae). J Zool 183:125-146

Allgäuer C, Honegger HW (1993) The antennal motor system of crickets: modulation of muscle contractions by a common inhibitor, DUM neurons, and proctolin. J Comp Physiol A Neuroethol Sens Neural Behav Physiol 173:485-494.

Bässler U (1972) Der Regelkreis des Kniesehnenreflexes bei der Stabheuschrecke Carausius morosus: Reaktionen auf passive Bewegungen der Tibia. Kybernetik 12:8-20.
Bässler U (1983) Neural basis of elementary behavior in stick insects. Berlin: Springer-Verlag.

Bässler U, Büschges A (1998) Pattern generation for walking movements of stick insects-multisensory control of a locomotor program. Brain Res Brain Res Rev 27:65-88.

Bässler U, Wegner U (1983) Motor output of the denervated thoracic ventral nerve cord in the stick insect Carausius morosus. J Exp Biol 105:127-145.

Bässler U, Wolf H, Stein W (2007) Functional recovery following manipulation of muscles and sense organs in the stick insect leg. J Comp Physiol A Neuroethol Sens Neural Behav Physiol 193:1151-1168.

Berkowitz A, Laurent G (1996) Local control of leg movements and motor patterns during grooming in locusts. J Neurosci 16:8067-8078.

Blümel M, Guschlbauer C, Gruhn M, Scharstein H, Hooper SL (2007a) Predicting swing phase movements of the stick insect FT joint. Paper presented at 100th Meeting of the Deutsche Zoologische Gesellschaft, Köln, Germany, September.

Blümel M, Guschlbauer C, Zehl L, Hooper SL, Büschges A (2007b) Investigating stick insect extensor muscle properties: an experimentally based muscle simulation. Paper presented at Seventh Meeting of the German Neuroscience Society/31st Göttingen Neurobiology Conference 2007, Göttingen, Germany, March-April.

Brown IE, Liinamaa TL, Loeb GE (1996) Relationships between range of motion, $\mathrm{L}_{0}$, and passive force in five strap-like muscles of the feline hind limb. J Morphol 230:69-77.

Büschges A, Gruhn M (2008) Mechanosensory feedback in walking: from joint control to locomotory patterns. Adv Insect Physiol 34:194-234.

Cappellini G, Ivanenko YP, Poppele RE, Lacquaniti F (2006) Motor patterns in human walking and running. J Neurophysiol 95:3426-3437.

Chiel HJ, Beer RD (1997) The brain has a body: adaptive behavior emerges from interactions of nervous system, body and environment. Trends Neurosci 20:553-557.

Crisco JJ, Panjabi MM (1990) Postural biomechanical stability and gross muscular architecture in the spine. In: Multiple muscle systems: biomechanics and movement organization (Winters J, Woo S, eds), pp 438450. New York: Springer.

Cropper EC, Lloyd PE, Reed W, Tenenbaum R, Kupfermann I, Weiss KR (1987) Multiple neuropeptides in cholinergic motor neurons of Aplysia - evidence for modulation intrinsic to the motor circuit. Proc Natl Acad Sci U S A 84:3486-3490.

Cropper EC, Price D, Tenenbaum R, Kupfermann I, Weiss KR (1990) Release of peptide cotransmitters from a cholinergic motor neuron under physiological conditions. Proc Natl Acad Sci U S A 87:933-937.

Cruse H, Bartling Ch (1995) Movement of joint angles in the legs of a walking insect Carausius morosus. J Insect Physiol 41:761-771.

Dudek DM, Full RJ (2007) An isolated insect leg's passive recovery from dorso-ventral perturbations. J Exp Biol 210:3209-3217.

Evans CG, Vilim FS, Harish O, Kupfermann I, Weiss KR, Cropper EC (1999) Modulation of radula opener muscles in Aplysia. J Neurophysiol 82:1339-1351.

Evans PD, O'Shea M (1978) The identification of an octopaminergic neurone and the modulation of a myogenic rhythm in the locust. J Exp Biol $73: 235-260$.

Fourtner CR (1981) Role of muscle in insect posture and locomotion. In: Locomotion and energetics in arthropods (Herreid CF, Fourtner CR, eds), pp 195-213. New York: Plenum.

Garcia M, Kuo A, Peattie A, Wang P, Full R (2000) Damping and size: insights and biological inspiration. Paper presented at First International Symposium on Adaptive Motion of Animals and Machines, Montreal, Canada, August.

Gatesy SM (1999) Guineafowl hind limb function. II. Electromyographic analysis and motor pattern evolution. J Morphol 240:127-142.

Godden DH (1974) The physiological mechanism of catalepsy in the stick insect Carausius morosus. J Comp Physiol 89:251-274.

Gracovetsky S, Farfan H, Lamy C (1986) The optimum spine. Spine 11:543-573.

Grillner S (1972) The role of muscle stiffness in meeting the changing postural and locomotor requirements for force development by the ankle extensors. Acta Physiol Scand 86:92-108.

Gruhn M, Hoffmann O, Dübbert M, Scharstein H, Büschges A (2006) Tethered stick insect walking: a modified slippery surface setup with optomo- 
tor stimulation and electrical monitoring of tarsal contact. J Neurosci Methods 158:195-206.

Guschlbauer C, Hooper SL, Scharstein H, Büschges A (2005) Contraction dynamics of the stick insect extensor tibiae muscle. Paper presented at Sixth Meeting of the German Neuroscience Society/30th Göttingen Neurobiology Conference 2005, Göttingen, Germany, February.

Guschlbauer C, Scharstein H, Büschges A (2007) The extensor tibiae muscle of the stick insect: biomechanical properties of an insect walking leg muscle. J Exp Biol 210:1092-1108.

Hale JP, Burrows M (1985) Innervation patterns of inhibitory motor neurones in the thorax of the locust. J Exp Biol 117:401-413.

Halliday DM, Conway BA, Christensen LO, Hansen NL, Petersen NP, Neilsen JB (2003) Functional coupling of motor units is modulated during walking in human subjects. J Neurophysiol 89:960-968.

Hamilton WJ (1972) Textbook of human anatomy. Baltimore: Harper and Row.

Hooper SL, Guschlbauer C, von Uckermann G, Büschges A (2006) Natural neural output that produces highly variable locomotory movements. J Neurophysiol 96:2072-2088.

Hooper SL, Guschlbauer C, von Uckermann G, Büschges A (2007a) Different motor neuron spike patterns produce contractions with very similar rises in graded slow muscles. J Neurophysiol 97:1428-1444.

Hooper SL, Guschlbauer C, von Uckermann G, Büschges A (2007b) Slow temporal filtering may largely explain the transformation of stick insect (Carausius morosus) extensor motor neuron activity into muscle movement. J Neurophysiol 98:1718-1732.

Hoyle G (1978) Intrinsic rhythm and basic tonus in insect skeletal muscle. J Exp Biol 73:173-203.

Jacobson RD, Hollyday M (1982) A behavioral and electromyographic study of walking in the chick. J Neurophysiol 48:238-256.

Lieberman DE, Raichlen DA, Pontzer H, Bramble DM, Cutright-Smith E (2006) The human gluteus maximus and its role in running. J Exp Biol 209:2143-2155.

Maloiy GMO, Alexander RM, Njau R, Jayes AS (1979) Allometry of the legs of running birds. J Zool 187:161-167.

Marquardt F (1940) Beiträge zur Anatomie der Muskulatur und der peripheren Nerven von Carausius (Dixippus) morosus. Zool Jahrb Abt Anat Ont Tiere 66:63-128.

Moore K (1983) Clinically oriented anatomy. Baltimore: Williams \& Wilkins.

Morris LG, Hooper SL (1997) Muscle response to changing neuronal input in the lobster (Panulirus interruptus) stomatogastric system: spike number-versus spike frequency-dependent domains. J Neurosci 17:5956-5971.

Morris LG, Hooper SL (1998) Muscle response to changing neuronal input in the lobster (Panulirus interruptus) stomatogastric system: slow muscle properties can transform rhythmic input into tonic output. J Neurosci 18:3433-3442.

Morris LG, Thuma JB, Hooper SL (2000) Muscles express motor patterns of non-innervating neural networks by filtering broad-band input. Nat Neurosci 3:245-250.

Nachemson A (1966) EMG studies on the vertebral portion of the psoas muscle. Acta Orthop Scand 37:177-190.

Nachemson A (1968) The possible importance of the psoas muscle for stabilization of the lumbar spine. Acta Orthop Scand 39:47-57.

Nauen JC, Shadwick RE (1999) The scaling of acceleratory aquatic locomotion: body size and tail-flip performance of the California spiny lobster Panulirus interruptus. J Exp Biol 202:3181-3193.

Nauen JC, Shadwick RE (2001) The dynamics and scaling of force production during the tail-flip escape response of the California spiny lobster Panulirus interruptus. J Exp Biol 204:1817-1830.
Page KL, Zakotnik J, Dürr V, Matheson T (2008) Motor control of aimed limb movements in an insect. J Neurophysiol 99:484-499.

Pearson KG, Acharya H, Fouad K (2005) A new electrode configuration for recording electromyographic activity in behaving mice. J Neurosci Methods 148:36-42.

Pearson KG, Bergman SJ (1969) Common inhibitory motoneurones in insects. J Exp Biol 50:445-471.

Pearson KG, Fourtner CR (1973) Identification of the somata of common inhibitory motoneurons in the metathoracic ganglion of the cockroach. Can J Zool 51:859-866.

Pollock CM, Shadwick RE (1994) Allometry of muscle, tendon, and elastic energy storage capacity in mammals. Am J Physiol 266:R1022-R1031.

Prochazka A, Trend P, Hulliger M, Vincent S (1989) Ensemble proprioceptive activity in the cat step cycle: towards a representative look-up chart. Prog Brain Res 80:61-74.

Rathmayer W, Bevengut M (1986) The common inhibitory neuron innervates every leg muscle in crabs. J Comp Physiol A Neuroethol Sens Neural Behav Physiol 158:665-668.

Roberts TJ, Marsh RL, Weyand PG, Taylor CR (1997) Muscular force in running turkeys: the economy of mimimizing work. Science 275:1113-1115.

Santaguida PL, McGill SM (1995) The psoas major muscle: a threedimensional geometric study. J Biomech 28:339-345.

Schmidt J, Grund M (2003) Rhythmic activity in a motor axon induced by axotomy. Neuroreport 14:1267-1271.

Stephens JA, Reinking RM, Stuart DG (1975) The motor units of cat medial gastrocnemius: electrical and mechanical properties as a function of muscle length. J Morphol 146:495-512.

Székely G, Czéh G, Vörös G (1969) The activity pattern of limb muscles in freely moving normal and deafferented newts. Exp Brain Res 9:53-62.

Thuma JB, Morris LG, Weaver AL, Hooper SL (2003) Lobster (Panulirus interruptus) pyloric muscles express the motor patterns of three neural networks, only one of which innervates the muscles. J Neurosci 23:8911-8920.

Tokuriki M, Aoki O (1995) Electromyographic activity of the hindlimb muscles during the walk, trot and canter. Equine Vet J 18:152-155.

Van Wassenbergh S, Herrel A, James RS, Aerts P (2007) Scaling of contractile properties of catfish feeding muscles. J Exp Biol 210:1183-1193.

Warwick R, Williams PL (1980) Gray's anatomy: descriptive and applied. London: Longman's Green Co.

Watson JT, Ritzmann RE, Zill SN, Pollack AJ (2002) Control of obstacle climbing in the cockroach, Blaberus discoidalis. I. Kinematics. J Comp Physiol 188:39-53.

Weidler DJ, Diecke PJ (1969) The role of cations in conduction in the central nervous system of the herbivorous insect Carausius morosus. $Z$ vergl Physiologie 64:372-399.

Weiss KR, Brezina V, Cropper EC, Hooper SL, Miller MW, Probst WC, Vilim FS, Kupfermann I (1992) Peptidergic co-transmission in Aplysia: functional implications for rhythmic behaviors. Experientia 48:456-463.

Wendler G (1964) Laufen und Stehen der Stabheuschrecke Carausius morosus: Sinnesborstenfelder in den Beingelenken als Glieder von Regelkreisen. J Comp Physiol A Neuroethol Sens Neural Behav Physiol 48:198-250.

Woodburne RT, Burkel WE (1988) Essentials of human anatomy. New York: Oxford UP.

Yox DP, DiCaprio RA, Fourtner CR (1982) Resting tension and posture in arthropods. J Exp Biol 96:421-425.

Zakotnik J, Matheson T, Dürr V (2006) Co-contraction and passive forces facilitate load compensation of aimed limb movements. J Neurosci 26: 4995-5007. 